\title{
Preparation of Polyhedral Copper Oxide Nanoparticles by Molten-salt Method and Their Catalytic Performance
}

\begin{abstract}
ZENG Tao ${ }^{1}$, BAI Yang ${ }^{1}$, LI Hao ${ }^{2}$, YAO Wei-Feng ${ }^{1}$, DONG Xian-Lin ${ }^{3}$
(1. Shanghai Key Laboratory of Materials Protection and Advanced Materials in Electric Power, Shanghai University of Electric Power, Shanghai 200090, China; 2. Huizhou University, Huizhou 516007, China; 3. Shanghai Institute of Ceramics, Chinese Academy of Sciences, Shanghai 200050, China)

Abstract: Polyhedral copper oxide $(\mathrm{CuO})$ nanoparticles were successfully prepared by a molten-salt method without any surfactant or template. Scanning electron microscopy images of the copper oxide samples demonstrated that the as-prepared nanoparticles have a polyhedral structure. The catalytic performances of copper oxide on the degradation of Rhodamine B in the presence of hydrogen peroxide were investigated. The results show that the polyhedral copper oxide nanoparticles exhibited much better catalytic performance in the degradation of Rhodamine B with hydrogen peroxide than commercial nano particles, even with smaller specific surface area. The possible reason can be attributed to the synergistic effect of high crystallinity and the exposed facets formed by polyhedral structure.
\end{abstract}

Key words: $\mathrm{CuO}$; polyhedral; catalyst; nanomaterials

Over the years, more and more attention has been paid to environment problems ${ }^{[1]}$, such as eliminating organic pollutants from wastewater. In the past decade, Advanced Oxidation Processes (AOPs) in which highly reactive hydroxyl radicals $(\bullet \mathrm{OH})$ are formed and result in the oxidative degradation of $\operatorname{organics}^{[2]}$, have been considered as promising alternatives for the treatment of organic pollution $^{[3-4]}$.

Among AOPs, $\mathrm{CuO} / \mathrm{H}_{2} \mathrm{O}_{2}$ system has received special attention due to its high efficiency ${ }^{[5-6]}$. In $\mathrm{CuO} / \mathrm{H}_{2} \mathrm{O}_{2}$ system, the degradation rate of contaminant is highly related to morphology and shapes of the $\mathrm{CuO}$ nanocatalysts. So, it is a feasible way to obtain $\mathrm{CuO}$ nanocatalysts with high catalytic performance by controlling their morphology during synthesis. According to reports, a number of differently shaped $\mathrm{CuO}$ nanomaterials have been successfully prepare $\mathrm{d}^{[7-8]}$. However, as far as we know, there is no report about the synthesis of polyhedral $\mathrm{CuO}$ nanoparticles and their catalytic applications in the degradation of organic pollutant with $\mathrm{H}_{2} \mathrm{O}_{2}$ until now. On the other hand, in the synthesis of $\mathrm{CuO}$ nanostructures with special morphology, the usages of capping agents will remarkably increase the expenditure of the synthesis. Besides, these capping agents will tightly bind on surface and occupy the active sites of the nanocatalysts, which may bring adverse impact on catalysis. In this regard, preparation of $\mathrm{CuO}$ nanocatalysts free of any capping agent is much more attractive. However, to the best of our knowledge, synthesis of $\mathrm{CuO}$ nanomaterials with specific morphology free of any capping agents has been seldom documented.

In this study, polyhedral $\mathrm{CuO}$ nanoparticles were prepared without the assistance of capping agents by a molten-salt method for the first time. The particle size could be controlled by adjusting the calcination temperature. It was found that the as-prepared $\mathrm{CuO}$ nanomaterials show excellent catalytic performance in the degradation of Rhodamine $\mathrm{B}$ with $\mathrm{H}_{2} \mathrm{O}_{2}$, which was much higher than that of recently reported $\mathrm{CuO}$ nanocatalyst ${ }^{[6-7]}$.

\section{Experimental}

In a typical procedure, $0.1 \mathrm{~mol} \mathrm{Cu}\left(\mathrm{NO}_{3}\right)_{2} \cdot 3 \mathrm{H}_{2} \mathrm{O}$ was dissolved in $200 \mathrm{~mL}$ distilled water. Then, $\mathrm{NH}_{3} \cdot \mathrm{H}_{2} \mathrm{O}$ $(15 \mathrm{wt} \%)$ was added to precipitate $\mathrm{Cu}^{2+}$ until the $\mathrm{pH}$ value of the mixed solution reached in a range from 6.0 to 8.0. With the addition of $\mathrm{NH}_{3} \cdot \mathrm{H}_{2} \mathrm{O}$, blue precipitation was gradually formed. The resulting mixed solution was fur-

Received date: 2014-09-23; Modified date: 2014-12-22; Published online: 2015-01-20

Foundation item: Innovation Program of Shanghai Municipal Education Commission (13YZ106); Natural Science Foundation of Guangdong Province (S2013010015681); High-level Talent Project of the University in Guangdong Province, "Dawn" Program of Shanghai Education Commission (11SG52); Science and Technology Commission of Shanghai Municipality (14DZ2261000)

Biography: ZENG Tao(1977-), associate professor. E-mail: zengtao626@hotmail.com

Corresponding author: LI Hao, associate professor. E-mail: lihao180@126.com 
ther heated at $60^{\circ} \mathrm{C}$ for $1.5 \mathrm{~h}$ under vigorous stirring. The precipitation was collected and washed successively for several times. After being dried in vacuum oven at $80^{\circ} \mathrm{C}$, the blue precipitation was obtained and used as a precursor. The precursor was mixed with $\mathrm{KNO}_{3}-\mathrm{NaNO}_{3}$ at a weight ratio of 45: 55. Herein, the weight ratio of $\mathrm{KNO}_{3}-\mathrm{NaNO}_{3}$ is 1: 1 . The above mixture was calcined for $2 \mathrm{~h}$ at different temperatures: $450^{\circ} \mathrm{C}, 550^{\circ} \mathrm{C}, 650^{\circ} \mathrm{C}$. Then, the resulting products were washed and dried at $80^{\circ} \mathrm{C}$ overnight.

In a typical process, $20 \mathrm{mg} \mathrm{CuO}$ catalysts were added into $100 \mathrm{~mL} \mathrm{RhB}$ solution $(10 \mathrm{mg} / \mathrm{L})$ under stirring, followed by addition of $2.5 \mathrm{~mL} \mathrm{H}_{2} \mathrm{O}_{2}$ solution (30wt\%). Then thermostatic waterbath was used to maintain the reaction temperature at $35^{\circ} \mathrm{C}$. During the catalytic process, reaction solution is sampled at different time intervals and its absorption intensity at $\lambda=550 \mathrm{~nm}$ was determined using a UV-visible spectrophotometer. To investigate the effect of reaction temperature, the catalytic degradation of $\mathrm{RhB}$ was also carried out at $25^{\circ} \mathrm{C}, 45^{\circ} \mathrm{C}, 55^{\circ} \mathrm{C}$.

The X-ray diffraction (XRD) pattern was recorded on a Bruker D8 Advance diffractometer using $\mathrm{Cu} \mathrm{K} \alpha$ radiation. The morphology of the $\mathrm{CuO}$ samples was observed using a JEM-2100F scanning electron microscope. The Brunauer-Emmett-Teller (BET) surface area was determined on a Gemini VII 2390 surface area analyzer.

\section{Results and discussion}

Figure 1 shows the XRD patterns of the $\mathrm{CuO}$ nanoparticles calcined at different temperatures. All of the diffraction peaks of $\mathrm{CuO}$ samples can be indexed to monoclinic phase of $\mathrm{CuO}$ (ICSD 48-1548). No other possible impurities were detected, indicating the high purity of the as-prepared polyhedral $\mathrm{CuO}$ nanomaterials. Notably, the intensity of the peaks increases slightly as the increase of

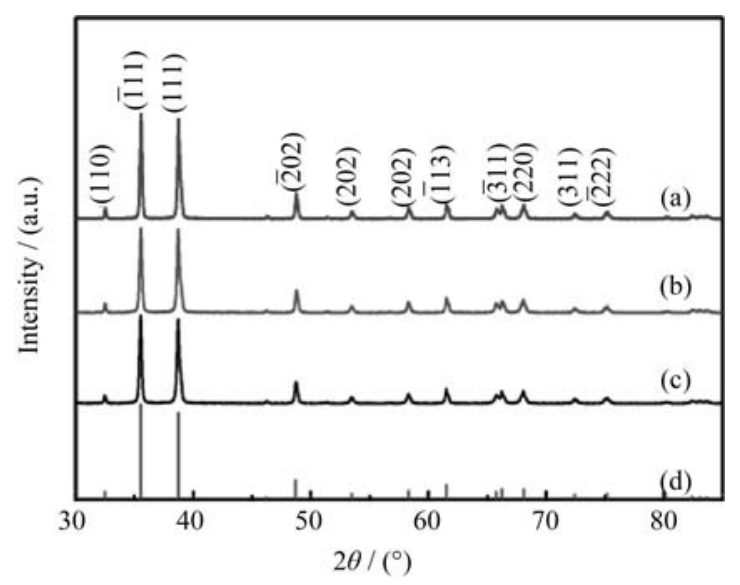

Fig. $1 \mathrm{XRD}$ patterns of the as-prepared $\mathrm{CuO}$ nanomaterials calcined at $650^{\circ} \mathrm{C}$ (a), $550^{\circ} \mathrm{C}$ (b), $450^{\circ} \mathrm{C}$ (c) and the standard $\mathrm{XRD}$ pattern of monoclinic phase $\mathrm{CuO}(\mathrm{d})$ the calcination temperature, giving a hint that the crystallinity of the sample rises when elevating the calcination temperature.

As shown in Fig. 2, the SEM images of $\mathrm{CuO}$ calcined at $450^{\circ} \mathrm{C}$ indicate that the particle size is about $100-150 \mathrm{~nm}$. Fig. 2(c) and 2(d) are the SEM images of polyhedral $\mathrm{CuO}$ nanoparticles calcined at $550^{\circ} \mathrm{C}$. Clearly, the average size of these $\mathrm{CuO}$ particles is $c a .200 \mathrm{~nm}$, which is larger than that of $\mathrm{CuO}$ calcined at $450^{\circ} \mathrm{C}$. As can be observed in Fig. 2(e) and $2(\mathrm{f})$, the particle size of $\mathrm{CuO}$ calcined at $650^{\circ} \mathrm{C}$ is about $300 \mathrm{~nm}$, which is larger than $\mathrm{CuO}$ particles calcined at $450^{\circ} \mathrm{C}$ and $550^{\circ} \mathrm{C}$. This suggests that the particle size of $\mathrm{CuO}$ can be controlled by adjusting the calcinations temperature.

Figure 3(a) demonstrated that the normalized concentration of $\mathrm{RhB}$ is $c a .0 .09,0.171,0.325$ and 0.65 at the reaction time of $100 \mathrm{~min}$ with the $\mathrm{CuO}$ calcined at $450^{\circ} \mathrm{C}$, $550^{\circ} \mathrm{C}, 650^{\circ} \mathrm{C}$ and the commercial $\mathrm{CuO}$ nanoparticles, respectively. Obviously, the three samples prepared by molten-salt method exhibit higher catalytic activity than the commercial $\mathrm{CuO}$ nanoparticles. As can be seen from Fig. 3, the catalytic degradation reaction follows a pseudo-first-order reaction, the rate constant of the $\mathrm{RhB}$ decomposition over $\mathrm{CuO}\left(450^{\circ} \mathrm{C}, 550^{\circ} \mathrm{C}, 650^{\circ} \mathrm{C}\right.$ and commercial $\mathrm{CuO}$ ) were estimated via the formula

$$
\ln \left(C / C_{0}\right)=-\mathrm{k} t
$$

In this formula, $\mathrm{k}$ is the apparent first order reaction rate constant of RhB degradation. The value of $k$ was obtained by calculating the slope of lines in Fig. 3(b) and the results
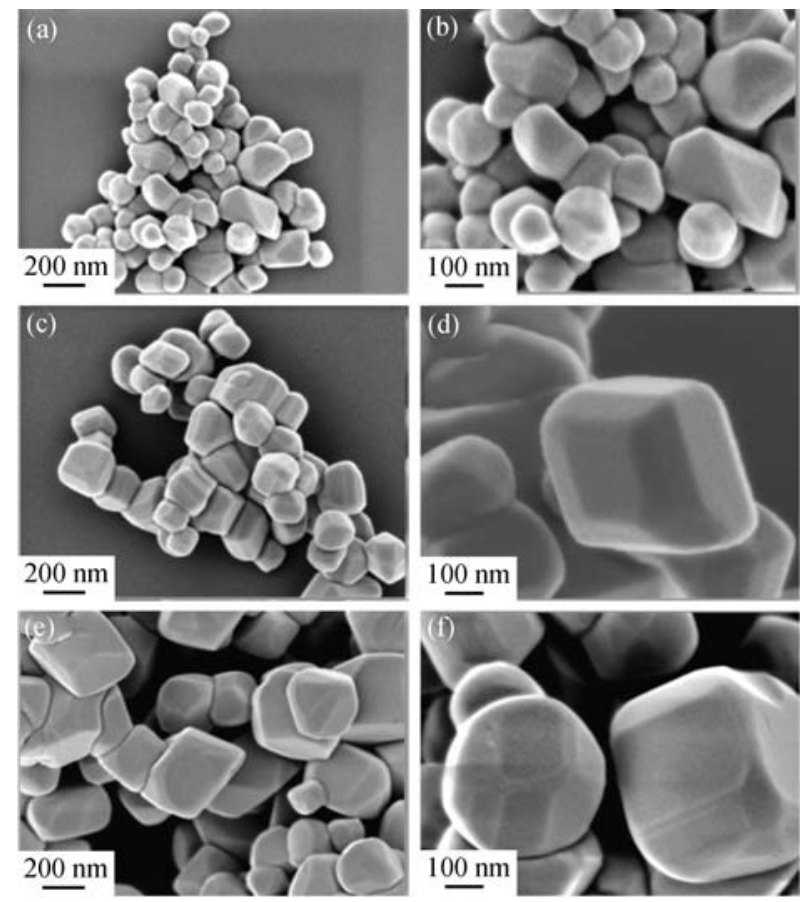

Fig. 2 SEM images of $\mathrm{CuO}$ nanostructures calcined at different temperatures
(a) (b) $450^{\circ} \mathrm{C}$; (c) (d) $550^{\circ} \mathrm{C}$; (e) (f) $650^{\circ} \mathrm{C}$ 

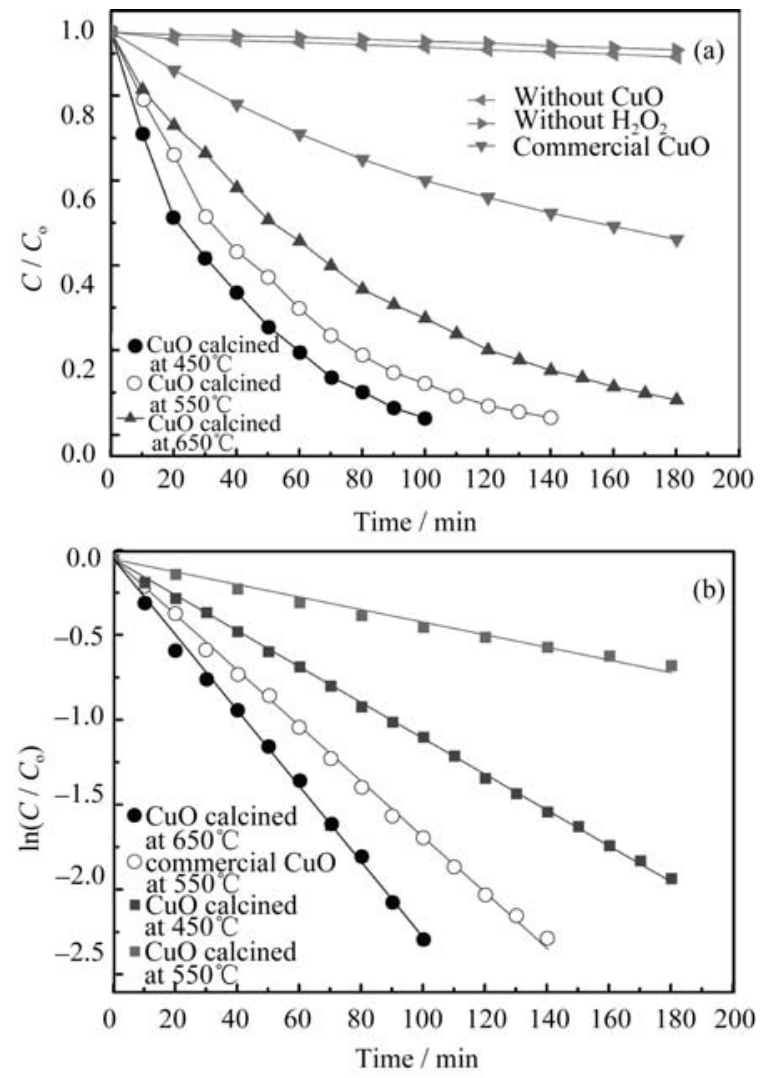

Fig. 3 Normalized concentration of RhB (a) and logarithm of normalized concentration of $\mathrm{RhB}(\mathrm{b})$ at different reaction time

are listed in Table 1. For comparison, the BET surface of different $\mathrm{CuO}$ catalysts was determined and the corresponding BET surface normalized rate constants was calculated, which are also shown in Table 1.

Clearly, the rate constant of $\mathrm{RhB}$ degradation in the presence of the as-prepared $\mathrm{CuO}$ as catalyst is much larger than that in the presence of the commercial $\mathrm{CuO}$ as cata- lyst despite that fact that the commercial catalyst has the largest BET surface. This demonstrates that our $\mathrm{CuO}$ nanocatalysts exhibit better catalytic activity than the commercial one. It has been demonstrated that the catalytic performance of nanocatalysts is closely associated with their morphology. Because they possess more edges, corners and faces, those shape-anisotropic nanocatalysts can provide more active sites for catalytic reactions. Therefore, the polyhedral $\mathrm{CuO}$ nanostructures in our case are supposed to have more active sites for the decomposition of $\mathrm{H}_{2} \mathrm{O}_{2}$ into free radicals, which will result in relatively high degradation rates of $\mathrm{RhB}$. On the other hand, it is observed that the BET surface of the as-prepared $\mathrm{CuO}$ samples decreases when the calcination temperature of samples increases. This is understandable because the particle sizes of polyhedral $\mathrm{CuO}$ nanoparticles increase as increasing the calcination temperature of samples, as observed in the TEM images. It is noted that the normalized rate constant is the largest when the $\mathrm{CuO}$ nanostructures calcined at $550^{\circ} \mathrm{C}$ act as catalyst. This implies that $\mathrm{CuO}$ nanostructures calcined at $550^{\circ} \mathrm{C}$ exhibit the highest intrinsic catalytic activity among the three $\mathrm{CuO}$ samples. As shown in Fig. 2, the shape of $\mathrm{CuO}$ nanostructures calcined at $550^{\circ} \mathrm{C}$ is more regular than those of the other two samples. It is possible that regular $\mathrm{CuO}$ nanostructures possess more active crystal surface for the RhB degradation. The detailed role of the morphology of the as-prepared $\mathrm{CuO}$ sample on $\mathrm{RhB}$ degradation is interesting but is not well understood, and further investigation is still necessary.

To investigate the effect of temperature on catalytic performance of $\mathrm{CuO}$, in this study, degradation of $\mathrm{RhB}$ at $25^{\circ} \mathrm{C}, 35^{\circ} \mathrm{C}, 45^{\circ} \mathrm{C}$ and $55^{\circ} \mathrm{C}$ is carried out. Like previous report $^{[7]}$, the curves in Fig. 4 indicate that the degradation

Table 1 Specific surface areas of different $\mathrm{CuO}$ nanomaterials, rate constants and surface area normalized rate constants in the oxidation of $\mathrm{RhB}$ when these $\mathrm{CuO}$ nanomaterials used as catalysts

\begin{tabular}{ccccc}
\hline Sample & Commercial $\mathrm{CuO}$ & $\mathrm{CuO}\left(450^{\circ} \mathrm{C}\right)$ & $\mathrm{CuO}\left(550^{\circ} \mathrm{C}\right)$ & $\mathrm{CuO}\left(650^{\circ} \mathrm{C}\right)$ \\
\hline Rate contant $/ \mathrm{min}^{-1}$ & 0.0039 & 0.0240 & 0.0176 & 0.0113 \\
Specific surface area $/\left(\mathrm{m}^{2} \cdot \mathrm{g}^{-1}\right)$ & 10.658 & 4.336 & 2.589 & 1.943 \\
Surface area normalized rate constant $/\left(\mathrm{min}^{-1} \cdot \mathrm{m}^{-2}\right)$ & 0.018 & 0.277 & 0.340 & 0.291 \\
\hline
\end{tabular}
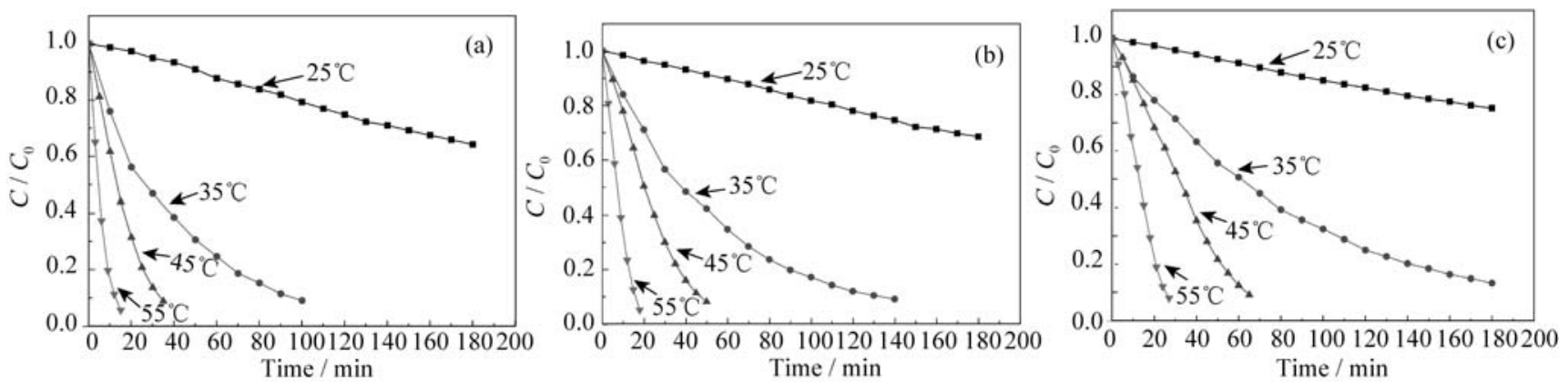

Fig. 4 The degradation efficiencies of $\mathrm{RhB}$ by different photocatalysts (a) $\mathrm{CuO}$ calcined at $450^{\circ} \mathrm{C}$; (b) $\mathrm{CuO}$ calcined at $550^{\circ} \mathrm{C}$; (c) $\mathrm{CuO}$ calcined at $650^{\circ} \mathrm{C}$ 
rate will rise with increasing reaction temperature. It takes about $20 \mathrm{~min}$ to $30 \mathrm{~min}$ to degrade $\mathrm{RhB}$ completely at $55^{\circ} \mathrm{C}$ and the degradation rate is much higher than the other three temperatures. This should be attribute to the fact that the conversion of $\mathrm{H}_{2} \mathrm{O}_{2}$ into $\cdot \mathrm{OH}$ is accelerated at higher temperature ${ }^{[1]}$.

\section{Conclusion}

In conclusion, polyhedral $\mathrm{CuO}$ nanoparticles were successfully synthesized through a facile molten salt method and exhibited much higher catalytic activities on $\mathrm{RhB}$ degradation than the commercial $\mathrm{CuO}$ nanoparticles. In this study, the factors affecting the catalytic performance were investigated. It was found that grain size, crystallinity, specific surface area, polyhedral structure and temperature in degradation process played key roles in determining catalytic activity.

\section{References:}

[1] INCHAURRONDO N S, MASSA P, FENOGLIO R, et al. Efficient catalytic wet peroxide oxidation of phenol at moderate temperature using a high-load supported copper catalyst. Chem. Eng. J., 2012, 198: 426-434.
[2] MASOMBOONA N, RATANATAMSKUL C, LU MING-CHUN. Kinetics of 2, 6-dimethylaniline oxidation by various Fenton processes. J. Hazard. Mater., 2011, 192(1): 347-353.

[3] KLAVARIOTIA M, MANTZAVINOS D, KASSINOS D. Removal of residual pharmaceuticals from aqueous systems by advanced oxidation processes. Environ. Int., 2009, 35(2): 402-417.

[4] OLLER I, MALATO S, SÁNCHEZ-PÉREZ J A. Combination of advanced oxidation processes and biological treatments for wastewater decontamination-a review. Sci. Total. Environ., 2011, 409(20): 4141-4166.

[5] ANU PRATHAP M U, KAUR B, SRIVASTAVA R. Hydrothermal synthesis of $\mathrm{CuO}$ micro/nanostructures and their applications in the oxidative degradation of methylene blue and non-enzymatic sensing. of glucose $/ \mathrm{H}_{2} \mathrm{O}_{2}$. J. Colloid. Interf. Sci., 2012, 370(1): 144-154.

[6] GAMAL M S, YEHIA F Z, DIMITRY O I H, et al. Ultrasonic assisted-Fenton-like degradation of nitrobenzene at neutral $\mathrm{pH}$ using nanosized oxides of $\mathrm{Fe}$ and $\mathrm{Cu}$. Ultrason. Sonochem., 2014, 21(4): 1358-1365.

[7] LI HAO, LIAO JIN-YUN, ZENG TAO. A facile synthesis of $\mathrm{CuO}$ nanowires and nanorods, and their catalytic activity in the oxidative degradation of Rhodamine B with hydrogen peroxide. Catal. Commun., 2014, 46: 169-173.

[8] PARK J C, KIM J, KWON H, et al. Gram-scale synthesis of $\mathrm{Cu}_{2} \mathrm{O}$ nanocubes and subsequent oxidation to $\mathrm{CuO}$ hollow nanostructures for lithium-ion battery anode materials. Adv. Mater, 2009, 21(7): 803-807.

\title{
熔盐法制备纳米多面体结构氧化铜及其催化性能研究
}

\author{
曾 涛 ${ }^{1}$, 白 杨 ${ }^{1}$, 李 浩 ${ }^{2}$, 姚伟峰 ${ }^{1}$, 董显林 ${ }^{3}$
}

(1. 上海电力学院, 上海市电力材料防护与新材料重点实验室, 上海 200090; 2. 惠州学院, 惠州 516007; 3. 中国科学

院 上海硅酸盐研究所, 上海 200050)

摘 要: 在不添加任何表面活性剂及模板剂的情况下用熔盐法制备出纳米氧化铜颗粒，用扫描电子显微镜观察发现制 备的纳米氧化铜呈现多面体结构, 且氧化铜晶粒大小可通过控制合成过程的煅烧温度来控制, 煅烧温度越高则晶粒 越大。在 $\mathrm{H}_{2} \mathrm{O}_{2}$ 作用下进行了纳米多面体结构氧化铜催化降解罗丹明 $\mathrm{B}$ 的研究。研究结果表明: 与商用纳米氧化铜相 比, 该实验制备的纳米氧化铜尽管具有更低的比表面积, 但是其催化性能得到显著的提升。这可能是因为纳米多面体 氧化铜的高结晶度及特定指数晶面的暴露所构成的协同作用大幅度提高了其催化性能。

关 键 词: 氧化铜; 多面体; 催化剂; 纳米材料

中图分类号: X703

文献标识码: A 